\title{
Histoplasma capsulatum in New England: A Case Study
}

\section{LORI-ANN CAMARA, KATERINA MIRAGLIA, SUSAN J. LECLAIR}

\begin{abstract}
ABBREVIATIONS: COPD - Chronic Obstructive Pulmonary Disease, CBC - Complete Blood Count, BUN - Blood Urea Nitrogen, EBV - Epstein Barr Virus, CMV - Cytomegalovirus, AIDS - Autoimmune Deficiency Syndrome
\end{abstract}

INDEX TERMS: Histoplasma capsulatum, Mould microscopic morphology, Biphasic fungal infections, Fungal pneumonia

Clin Lab Sci 2014;27(1):6

Lori-Ann Camara, MLS(ASCP) ${ }^{C M}$, St. Luke's Hospital, New Bedford, MA 02740

Katerina Miraglia, D.C., $M L S(A S C P)^{C M}$, Department of Medical Laboratory Science, University of Massachusetts, Dartmouth, MA 02747-2300

Susan J. Leclair, Ph.D., Department of Medical Laboratory Science, University of Massachusetts, 285 Old Westport Road, Dartmouth, MA

Address for Correspondence: Susan J. Leclair, Ph.D., Department of Medical Laboratory Science, University of Massachusetts, 285 Old Westport Road, Dartmouth, MA 02747-2300, 508-999-8786, sleclair@umassd.edu

Overview: A healthy adult experienced a necrotic lesion on her back. She developed a reduced appetite, profound weakness, and fever. Routine x-rays and CAT scans demonstrated bilateral hilar adenopathy and patchy infiltrates. During bronchoscopy, biopsies and cultures for bacteria and fungi were taken.

Patient History: A 24-year-old female was admitted to the hospital after treatment by her primary care physician for a necrotic skin lesion on her back. She is a social worker in a large urban area in the Northeast quadrant of the country and recently returned from a vacation in Honduras where she experienced a "bite" on her back. Approximately 10 days after her return, she experienced generalized weakness, night sweats, chills and headaches. She also states that she has experienced a significant drop in appetite. She did not complain of any chest pain but commented about heaviness behind her sternum. Medical imaging confirmed the presence of abdominal and inguinal adenopathy. The only relevant family history included a parent with COPD due to smoking and a paternal uncle with sarcoidosis. Given the continued presence of a now necrotic lesion, her primary care physician initiated a course of doxycycline for a suspected rickettsial infection. The necrotic lesion resolved but the systemic symptoms persisted and, together with the imagining results, a bronchoscopy was justified.

Relevant Medical History: The patient has been healthy although her childhood medical history includes bouts of asthma that diminished over time. She stated that she has not have an instance of asthma for at least 10 years. Initial potential diagnoses included lymphoma, tuberculosis, disseminated bacterial, fungal or parasitic disease and sarcoidosis. Biopsies and cultures were taken from the sites of adenopathy and immunologic studies were ordered for Lyme Disease, Rickettsia spp., and Erlichia spp.

Her admission CBC in Table 1 showed a decreased white cell count with neutropenia, eosinophilia, and monocytosis suggesting an acute inflammation with high antigenic stimulation which is also reflected in the increased erythrocyte sedimentation rate. The common metabolic panel seen in Table 2 revealed hypoalbuminenia that could account for the decreased anion gap. ${ }^{1}$ Hypoalbuminemia is associated with poor diet which correlated well with her history. The decreased BUN/Creatinine ratio was not considered significant due to the BUN value which was explained by her lack of appetite and, specifically, a lack of high protein foods in recent days. With both values within 
reference intervals, follow up with a nutritionist was suggested.

Table 1. Report of relevant hematology laboratory testing at time of admission

\begin{tabular}{|c|c|c|c|}
\hline Test & \multicolumn{2}{|c|}{ Patient Result } & Reference Intervals \\
\hline WBC & \multicolumn{2}{|c|}{$3.8 \times 10^{9} / \mathrm{L}$} & $4.5-11.0$ \\
\hline $\mathrm{RBC}$ & \multicolumn{2}{|l|}{$3.8 \times 10^{12} / \mathrm{L}$} & $4.2-4.6$ \\
\hline $\mathrm{Hgb}$ & \multicolumn{2}{|l|}{$13.3 \mathrm{~g} / \mathrm{dL}$} & $12.8-15.2$ \\
\hline $\mathrm{HCT}$ & \multicolumn{2}{|l|}{$38.5 \%$} & $38-45$ \\
\hline $\mathrm{MCV}$ & \multicolumn{2}{|l|}{$83.9 \mathrm{fL}$} & $80-94$ \\
\hline $\mathrm{MCH}$ & \multicolumn{2}{|l|}{$29.0 \mathrm{pg}$} & $27-32$ \\
\hline $\mathrm{MCHC}$ & \multicolumn{2}{|l|}{$34.5 \mathrm{~g} / \mathrm{dl}$} & $32-36$ \\
\hline RDW & \multicolumn{2}{|l|}{$12.5 \%$} & $11.0-14.5$ \\
\hline PLT & \multicolumn{2}{|l|}{$194 \times 10^{9} / \mathrm{L}$} & $150-450$ \\
\hline MPV & \multicolumn{2}{|l|}{$6.8 \%$} & $6.8-10$ \\
\hline NE\% & \multicolumn{2}{|l|}{$50.3 \%$} & $45-78$ \\
\hline LY\% & \multicolumn{2}{|l|}{$28.1 \%$} & $16-45$ \\
\hline MO\% & $15.1 \%$ & HIGH & $3-12$ \\
\hline $\mathrm{EO} \%$ & $5.7 \%$ & HIGH & $0-5$ \\
\hline $\mathrm{BA} \%$ & $0.5 \%$ & & $0-2$ \\
\hline NE Intermediate Form & $3.0 \%$ & & 0 \\
\hline NE \# & $1.9 \times 10^{9} / \mathrm{L}$ & & $2.0-7.7$ \\
\hline LY \# & $0.6 \times 10^{9} / \mathrm{L}$ & & $1.0-4.8$ \\
\hline $\mathrm{MO} \#$ & $0.6 \times 10^{9} / \mathrm{L}$ & & $0.0-0.8$ \\
\hline $\mathrm{EO} \#$ & $0.2 \times 10^{9} / \mathrm{L}$ & & $0.0-0.5$ \\
\hline BA \# & $0.0 \times 10^{9} / \mathrm{L}$ & & $0.0-0.2$ \\
\hline ESR & $40 \mathrm{~mm} / \mathrm{hr}$ & HIGH & $0-15$ \\
\hline
\end{tabular}

Table 2. Report of relevant chemistry laboratory testing at time of admission

\begin{tabular}{|c|c|c|}
\hline Test & Patient Result & Reference Intervals \\
\hline Sodium & $138 \mathrm{mEq} / \mathrm{L}$ & $135-144$ \\
\hline Potassium & $4.3 \mathrm{mEq} / \mathrm{L}$ & $3.3-5.1$ \\
\hline Chloride & $102 \mathrm{mEq} / \mathrm{L}$ & $98-109$ \\
\hline Carbon Dioxide & $32 \mathrm{mmol} / \mathrm{L}$ & $23-32$ \\
\hline Anion gap & $4 \mathrm{mEq} / \mathrm{L}$ LOW & $7-16$ \\
\hline BUN & $8 \mathrm{mg} / \mathrm{dL}$ & $5-25$ \\
\hline Creatinine & $1.1 \mathrm{mg} / \mathrm{dL}$ & $0.8-1.4$ \\
\hline $\mathrm{BUN} /$ creatinine ratio & 8.9 LOW & $12.0-20.0$ \\
\hline Total Protein & 6.1 & 6.0 to 8.3 \\
\hline Albumin & LOW & $3.6-4.9$ \\
\hline
\end{tabular}

\section{Differential Diagnosis}

Initial pathologic examination of the lymph nodes showed multiple granulomas. Granulomas can form when macrophages ingest but do not completely degrade or eliminate foreign material. ${ }^{2}$ Initiating events of granuloma formation include the presence of nonliving material such as particulate air pollutants, autoimmune disorders such as sarcoidosis, and living substances such as bacteria, fungi and parasites. Granulomas are characterized by a combination of lymphocytes, neutrophils, eosinophils, multinucleated giant cells, fibroblasts and collagen (fibrosis). The relative number of cells can be a clue to the cause of the granuloma. For example, granulomas with numerous eosinophils may signify coccidioidomycosis or allergic bronchopulmonary fungal disease, while granulomas with numerous neutrophils might reflect blastomycosis or cat-scratch disease. ${ }^{3}$

Histological examination of the lymph nodes demonstrated no malignant cells or architectural distortion due to a malignancy, eliminating the potential for either Hodgkin or Non-Hodgkin Lymphoma. With potential malignant disorders eliminated, the investigation focused on sarcoidosis due to the family history and infections characterized by pulmonary granulomas such as tuberculosis, histoplasmosis, coccidioidomycosis or common viral disorders.

The cause of sarcoidosis is unknown with infections, autoimmune disease and genetic mutations having been implicated. ${ }^{4}$ A common disease, sarcoidosis has no specific age, race or gender predilections. It commonly occurs in adults from $20-24$ years of age. The current assumption is an interaction between a genetic risk and a triggering event. While tissue biopsy is a significant test to assess the potential for a diagnosis of sarcoidosis, other laboratory tests are helpful. These include increased values for angiotensin-converting enzyme (ASCE) assay and liver function studies to include Albumin, Alanine Transaminase, Alkaline Phosphatase, Aspartate Transaminase, Bilirubin, and Lactate Ddehyrogenase. ${ }^{5}$ In this situation, however, all of these tests, save the albumin, were within reference intervals.

The preliminary bacteriological reports of the biopsies showed no bacterial growth with Gram stain and acidfast stain. Additional samples from both the bronchoscopy and the hilar node biopsies were submitted for fungal culture. Tuberculosis was eliminated as the cause for the negative acid-fast stain and correlated with the negative $\mathrm{T}$-cell interferon release skin test. ${ }^{6}$

Serological tests for Brucella, Coccidioides, Dengue fever, rickettsia, spotted fever, CMV, EBV, Q fever, and 
Table 3. Report of relevant immunology laboratory testing

\begin{tabular}{|c|c|c|c|}
\hline Test & Patient Result & \multicolumn{2}{|l|}{ Reference Intervals } \\
\hline Brucella IgG Antibody & Negative & \multicolumn{2}{|l|}{ Negative } \\
\hline Brucella IgM Antibody & Negative & \multicolumn{2}{|l|}{ Negative } \\
\hline Brucella Ab Interpretation & $\begin{array}{l}\text { Recommend repeat in } \\
14-21 \text { days if recent } \\
\text { infection is suspected }\end{array}$ & & \\
\hline Coccidiodes $\mathrm{Ab}(\mathrm{CF})$ & $1: 4$ & \multicolumn{2}{|l|}{ Negative } \\
\hline Coccidioides IgG Antibody & Negative & \multicolumn{2}{|l|}{ Negative } \\
\hline Coccidioides IgM Antibody & Negative & \multicolumn{2}{|l|}{ Negative } \\
\hline CMV IgM antibody & Negative & \multicolumn{2}{|l|}{ Negative } \\
\hline CMV DNA Quant PCR & None detected & \multicolumn{2}{|l|}{ None detected } \\
\hline CMV DNA PCR copies/mL & None detected & \multicolumn{2}{|l|}{ None detected } \\
\hline Dengue Fever IgG Antibody & 0.2 & \multicolumn{2}{|l|}{$<0.90$} \\
\hline Dengue Fever IgM Antibody & 0.52 & \multicolumn{2}{|l|}{$<0.90$} \\
\hline EBV capsid antigen - IgG antibody & Negative & \multicolumn{2}{|l|}{ Negative } \\
\hline EBV capsid antigen - IgM antibody & Negative & \multicolumn{2}{|l|}{ Negative } \\
\hline EBV nuclear antigen Antibody & Positive & \multicolumn{2}{|c|}{$\begin{array}{l}90 \% \text { of the adult population will } \\
\text { have been infected with EBV. } \\
\text { previously }\end{array}$} \\
\hline EBV DNA Quant PCR & $<2000$ & \multicolumn{2}{|c|}{ None detected } \\
\hline EBV 95\% Conf Intervals & & \multicolumn{2}{|c|}{$\begin{array}{l}\text { Results may not be reproducible } \\
\text { due to low copy level. }\end{array}$} \\
\hline \multicolumn{4}{|l|}{ EBV interpretation } \\
\hline Malaria smear & None seen & \multicolumn{2}{|l|}{ None seen } \\
\hline Q Fever Phase I IgG Antibody & Negative & \multicolumn{2}{|l|}{ Negative } \\
\hline Q Fever Phase I IgM Antibody & Negative & \multicolumn{2}{|l|}{ Negative } \\
\hline Q Fever Phase II IgG Antibody & Negative & \multicolumn{2}{|l|}{ Negative } \\
\hline Q Fever Phase II IgM Antibody & Negative & \multicolumn{2}{|l|}{ Negative } \\
\hline Spotted Fever Group IgG & $<1: 64$ & \multicolumn{2}{|l|}{$<1: 64$} \\
\hline Spotted Fever Group IgM & $<1: 64$ & \multicolumn{2}{|l|}{$<1: 64$} \\
\hline Rickettsia IgG Antibody & Not detected & \multicolumn{2}{|l|}{ Not detected } \\
\hline Rickettsia IgM Antibody & Not detected & \multicolumn{2}{|l|}{ Not detected } \\
\hline Ricketsia typhii IgG & Not detected & \multicolumn{2}{|l|}{ Not detected } \\
\hline Rickettsia typhii IgM & Not detected & \multicolumn{2}{|l|}{ Not detected } \\
\hline Beta-2 glucan assay & $<31$ & $\begin{array}{l}\text { Negative: } \\
\text { Indeterminate: } \\
\text { Positive: }\end{array}$ & $\begin{array}{l}<60 \mathrm{pg} / \mathrm{mL} \\
>60 \text { to }<80 \mathrm{pg} / \mathrm{mL} \\
>\neg 80 \mathrm{pg} / \mathrm{mL}\end{array}$ \\
\hline Histoplasma capsulatum Quant & 0.53 & \multicolumn{2}{|l|}{ None detected } \\
\hline
\end{tabular}

Lyme disease were all negative (Table 3). Evaluation of blood film for malaria smear was also negative. Serological tests for Histoplasma capsulatum were positive.

Twenty-four hour fungal cultures on BHIA with $10 \%$ blood plates were incubated at $37^{\circ} \mathrm{C}$ and showed ivorywhite colonies with no hemolysis. Gram stain smears of these colonies demonstrated classic yeast formations. One week later, growth of colonies with a fluffy white central area fading into a light brown in color, and pale yellow white to brown in color were seen on Sabouraud's dextrose agar. The typical growth at $37^{\circ} \mathrm{C}$ illustrates a yeast-phase growth with Histoplasma capsulatum var capsulatum. This type of growth may happen in a clinical laboratory in as little as a few days, when it will produce an initially rough, mucoid, creamcolored colony that may turn brown with age. A Giemsa stained slide would demonstrate the typical findings of small $(2-4 \mu \mathrm{m})$, oval, budding cells. These 
are best recovered with Brain Heart Infusion Agar of Todd-Hewitt broth.

Figure 1 illustrates the mould-phase growth seen in this case with Histoplasma capsulatum var capsulatum. In the clinical laboratory this type of growth may happen at $25-30^{\circ} \mathrm{C}$ in $7-45$ days ( 11 days in this case) when it will produce a moist, waxy, cerebriform colony on blood agar or a cottony, white to brown colony on Sabouraud Dextrose Agar (or Brain Infusion Agar) with age.

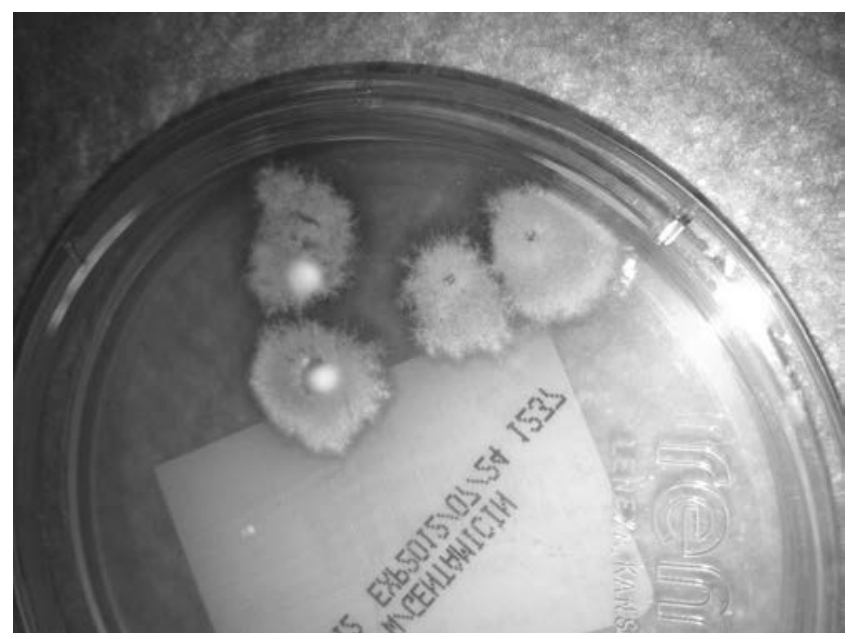

Figure 1. Growth on Sabauraud Dextrose Agar after 11 days at room temperature.

Figure 2 shows the Lacto-Phenol Cotton Blue slide preparation from this case demonstrating the typical small hyphae that are hyaline and septate producing round to teardrop macroaleuriospores (macroconidia), 7-15 $\mu \mathrm{m}$ in size on short lateral branches that can easily be confused with Sepedonium spp. (which are not thermally dimorphic). The macroaleureospores that are typically spherical and tuberculated are most diagnostic. ${ }^{7}$ Early on during the mould-phase of the clinical laboratory culture, the microscopic examination revealed round or pear-shaped microconidia $(2-5 \mu \mathrm{m})$ as also seen in Figure 2.

\section{Discussion}

Histoplasmosis is an mycosis caused by Histoplasma capsulatum, a dimorphic fungus that exists in mold form in the environment and as yeast at $37^{\circ} \mathrm{C}$. Histoplasma capsulatum is found world wide and is endemic in central United States, especially in the Mississippi and Ohio River valleys. There are an estimated 500,000 cases of histoplasmosis annually in the United States. ${ }^{8}$ Histoplasma was once subdivided into three varieties, $H$. capsulatum, $H$. duboisii, and $H$. farciminosum, however molecular testing has shown there are genetically distinct geographical populations of the same species, $H$. capsulatum. ${ }^{9}$ The microorganism is found in soil that is contaminated by bird or bat droppings. Infection occurs by inhalation of windborne spores. ${ }^{10}$ In the 21 st century, instances of Histoplasma infection have been seen in patients throughout the world due, in most part, to tours of countries in which this fungus is indigenous. ${ }^{11}$

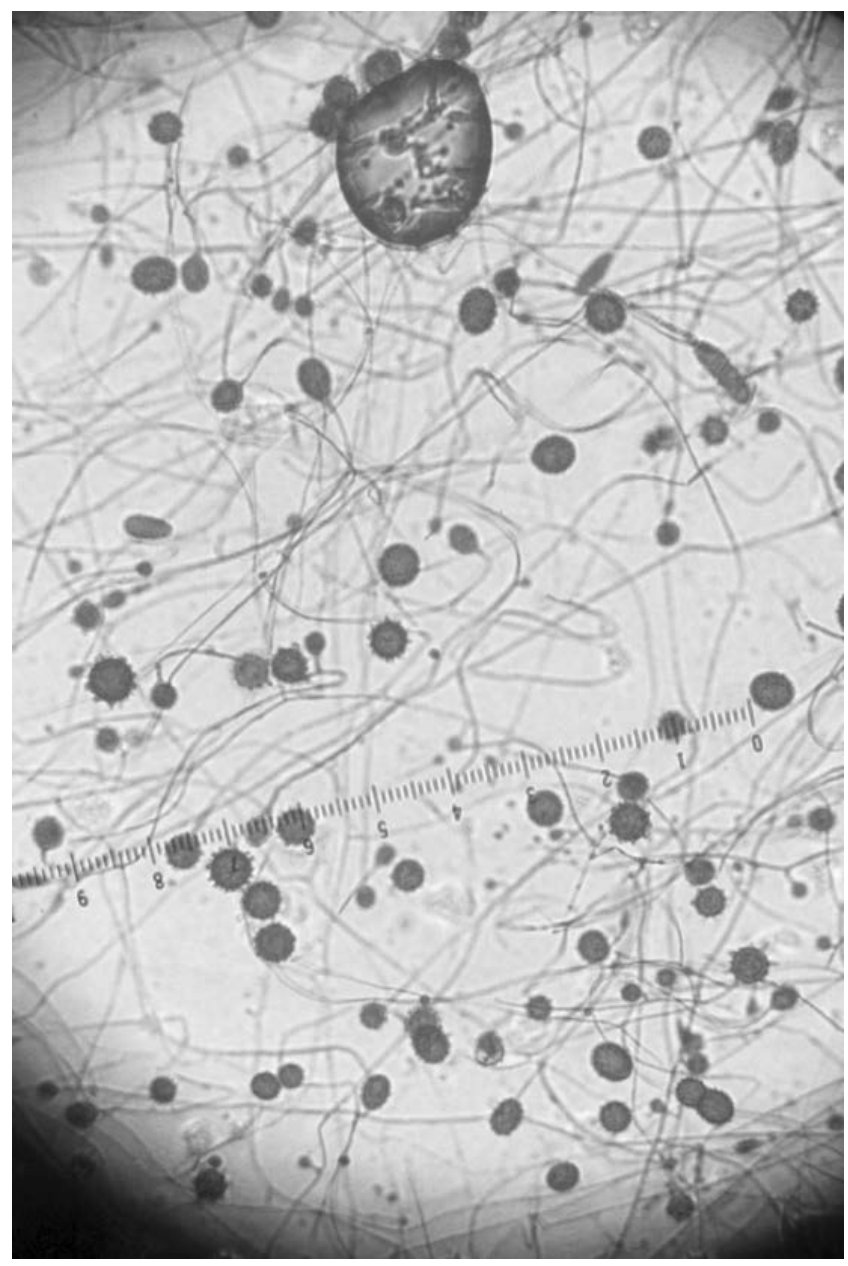

Figure 2. A high power (40x) view of a Lactophenol Cotton Blue stained smear of the mould phase growth at room temperature.

In most cases the patient is asymptomatic and the infection is self-limiting. In other cases, acute pulmonary infections or severe, progressive disseminated infection develops. ${ }^{12}$ Other sequelae include bronchiolithiasis, mediastinal graunuloma, and mediastinal fibrosis. ${ }^{13}$ The severity of infection is based 


\section{CLINICAL PRACTICE}

on the immune status of the patient and by a concentration of exposure to spores. A large amount of spore exposure over a short period of time may result in fulminant disease despite the immune status of the patient. $^{14}$

Granulomatous pulmonary nodules are common in endemic areas. Differential diagnosis for pulmonary nodules include infectious diseases such as tuberculosis, coccidiomycosis, blastomycosis, and cryptococcosis. Non-infections/benign causes may be sarcoidosis, amyloidosis, hamartomas, rheumatoid nodules, and round atelectasis. Malignant causes must also be ruled out and include primary lung cancer, carcinoid tumors, and metastatic disease. ${ }^{15}$

In histoplasmosis, pulmonary calcifications are greater than $4 \mathrm{~mm}$ with lymph node calcifications greater than $10 \mathrm{~mm}$. This differentiates it from tuberculosis, which consists of smaller calcifications. Splenic calcifications in histoplasmosis are more numerous and larger than those that occur with tuberculosis. ${ }^{16}$

Microconidia are inhaled and develop into yeast form in the lungs. The infective dose of the microorganism is unknown. Neutrophils, lymphocytes, and macrophages respond to the infection. Interleukin-12 and interferon gamma aid the macrophages in destroying the organism. ${ }^{17}$ Macrophages engulf the yeast and the yeast cells invade the macrophages and multiply within them. From there they are able to migrate to regional lymph nodes and then disseminate to other areas of the body hematogenously.

Disseminated histoplasmosis is rare and often occurs in immunocompromised patients. These patients have a defective cell mediated immunity, which may be caused by cytotoxic drugs, corticosteroids, immunosuppressive drugs used after organ transplantation, AIDS, and in those who are very young (less than 2 years of age), and the elderly (older than 54 years old). ${ }^{18}$

Patients may be asymptomatic or symptomatic. Common signs and symptoms especially in disseminated infection include fever, persistent dry cough, weight loss, anorexia, malaise, abdominal pain, chest pain, nausea, vomiting, and diarrhea. The patient may have hepatosplenomegaly. Acute pulmonary infection occurs more often in infants and the immunocompromised. Radiologic findings may be normal. The most common abnormal chest $\mathrm{x}$-ray findings are diffuse, small nodular opacities, pleural effusions, and lymphadenopathy in immunocompetent patients.

Chronic pulmonary infection is progressive and occurs mostly in elderly men. It is strongly associated with chronic obstructive pulmonary disease. It occurs usually in the apices of the lungs, most commonly in the right upper lobe.

\section{Laboratory diagnosis}

Histoplasma capsulatum is a thermally dimorphic fungus. It is a slow grower taking from 15-20 days up to 8 weeks for the mycelial form to grow. It is white to brown or pinkish in color with a fine, dense cottony texture at $25-30^{\circ} \mathrm{C}$ on Sabouraud Dextrose Agar. There is growth of moist, white yeast colonies on Brain Heart Infusion agar at $35-37^{\circ} \mathrm{C}$.

Microscopic appearance of mycelial form at $25-30^{\circ} \mathrm{C}$ consists of septate hyphae with round microconidia 2-5 micrometers in diameter on short branches or directly on the sides of the hyphae. In the later stage of growth, large, thick walled, round macroconidia (7-15 micrometers) with short cylindrical projections may be observed.

Microscopically, the yeast form is small, round or oval budding yeast cells with a narrow neck. They are often found intracellularly in macrophages.

The gold standard for laboratory diagnosis of histoplasmosis is culture of a body sample such as bronchioalveolar lavage, bone marrow, skin, or blood. Gomori methenamine silver (GMS) stain of tissue sections can reveal fibrocaseous nodules with yeast organisms. ${ }^{19}$ Cultures are usually negative in patients with mild to moderate acute disease. They are more likely to be positive in patients with disseminated disease.

The two most common antibody assays for histoplasmosis are the complement fixation method (CF), which uses mycelial and yeast antigens, and the immunodiffiusion method (ID), an assay for $\mathrm{H}$ and $\mathrm{M}$ bands. ${ }^{19}$ The $\mathrm{M}$ band is present in acute and chronic infections, and may persist after infection has resolved. 


\section{CLINICAL PRACTICE}

The $\mathrm{H}$ band is not commonly seen. Its presence is suggestive of acute or recent infection. ${ }^{20}$ Histoplasma antibodies may take 2-6 weeks to develop with acute disease, therefore antibody testing should be performed 2-6 weeks after exposure to the organism.

The CF method is more sensitive than the ID method, but it is less specific. The ID method has many false positive reactions in cases of other fungal infections such as blastomycosis, and coccidiomycosis. It may also have false positive in cases of tuberculosis, lymphoma and sarcoidosis. ${ }^{21}$ Antibody testing is most useful in patients with chronic histoplamsosis or acute pulmonary histoplasmosis.

Enzyme immunoassays have higher sensitivity in urine than serum. False positives may occur in cases of blastomycosis, coccidiomycosis, paracoccidiomycosis, and Penicillium marneffei infections. Serum antigen testing has low sensitivity in immunocompetent patients.

There are pitfalls to both antigen and antibody testing in immunocompetent patients. A PCR assay is available with a high degree of specificity although the urine antigen method appears to be more sensitive. ${ }^{22}$ A single negative test does not rule out histoplasmosis. Clinical presentation is variable, which may make diagnosis more difficult. Travel history or residence in endemic areas may help with diagnosis.

Although most Histoplasma infections can be treated with some form of azole such as itraconazole, monoclonal antibodies target fungal cell surface proteins or stimulatory molecules of the host. ${ }^{23}$ Mild to moderate infections require treatment with itraconazole. Severe pulmonary and disseminated infections require Amphotericin B therapy.

\section{Conclusion}

The patient was successfully treated with itraconazole on an outpatient basis. The patient was first concerned with a bite on her back but she also presented with pulmonary signs that were suggestive of a pulmonary infection. Histoplasma was considered only in the light of the patient's recent travel to an area in which it is endemic but was not originally considered to be of high interest because she lived in New England. ${ }^{24}$ Cultures grew the yeast form and mould forms of Histoplasma capsulatum and serological testing confirmed its presence. The increase in the frequency of Histoplasma identification may also be connected with global climate change, suggesting that areas once not known for Histoplasma can and are being colonized. ${ }^{25}$ Given the prevailing winds of the northern hemisphere, it would seem logical to suppose that areas in which this increase may occur include the entire east coast of the United States.

\section{REFERENCES}

1 Kraut JA. Serum anion gap: Its uses and limitations in clinical medicine CJASN. 2007;2(1):162-74.

2 Woodard BH, Rosenberg SI, Farnham R, Adams DO. Incidence and nature of primary granulomatous inflammation in surgically removed material. AJSurg.Pathol. 1982;6(2): 11929.

3 Mukhopadhyay, S; Farver CF, Vaszar LT, Dempsey OJ, Popper HH, Mani H, et al. "Causes of pulmonary granulomas: a retrospective study of 500 cases from seven countries". J Clin Pathol 2012;1:51-7.

4 National Heart Lung and Blood Institute website. What is sarcoidosis? Available at http://www.nhlbi.nih.gov/health/dci/ Diseases/sarc/sar_causes.html. Page last updated May 1, 2011. Accessed August 12, 2012.

5 Zielonka TM, Zycinska K, Chorostowska-Wynimko J, Filewska M, Bialas B, Obrowski MH, et al. Angiogenic activity of sera from interstitial lung disease patients in relation to angiotensin-converting enzyme activity. Adv Exp Med Biol. 2013;756:213-21.

6 Ewer K, Deeks J,Alvarez L et al. Comparison of T cell based assay with tuberculin skin test for diagnosis of Mycobacterium tuberculosis infection in a school tuberculosis outbreak. Lancet 2003;361:1168-73.

7 Salimnia H, Brown P, Lephart P, Fairfax MR. Hyphal and yeast forms of Histoplasma capsulatum growing within 5 days in an automated bacterial blood culture system. J Clin Microbiol. 2012;50(8):2833-4.

8 Wheat LJ, Kauffman CA. Histoplasmosis. Infect Dis Clin North Am. 2003;17(1):1-19, vii.

9 Kasuga T, WHitle TJ, Koenig G, McEwen J, Restrepo A, et al. Phylogeography of the fungal pathogen Hsitoplasma capsulatum. Mol. Ecol 2003;12(12):3383-401.

10 Baddley JW, Winthrop, KL, Patkar, NM, Delzell, Beukelman $\mathrm{T}$, Fenglong $\mathrm{X}$, et al. Geographic distribution of endemic fungal infections among older persons, United States, EID 2011;17(9):1664-9.

11 Nygard K, Brantsaeter A, Feruglio S, Ravn J, Dotevall L, Hasle G, Myrvang B. Histoplasmosis among travelers to Central America. Available from www.ncbi.nlm.nih.gov/pubmed/ 17086244? . Accessed May 26, 2013.

12 Luo G, Gerrety MJ, DeBurger B, Pfeffer J, McMasters R, Mortensen J. Case twenty two: a disseminated infection. Continuing Education Topics and Issues 2012;22-3.

13 Arango M, Castañeda E, Agudelo CI, De Bedout C, Agudelo CA, Tobón A, et al. Colombian Histoplasmosis Study Group. Histoplasmosis: results of the Colombian national survey, 1992-2008 Biomedica. 2011;31(3):344-56. 


\section{CLINICAL PRACTICE}

14 Zhou P, Sieve MC, Tewari RP, Seder RA. Interleukin-12 modulates the protective immune response in SCID mice infected with Histoplasma capsulatum. Infect Immun. 1997;65(3):936-42.

15 Gill P, Malik A, Lall C. Histoplasmosis: the radiologic mimic and the disease spectrum- a guide for the practicing radiologist. Applied Radiology 2006:24-37.

16 Gurney JW, Conces DJ. Pulmonary histoplasmosis.. Radiology. 1996;199(2):297-306.

17 Threlkeld ZD, Broughton R, Khan GQ, Berger JR. Isolated Histoplasma capsulatum meningoencephalitis in an immunocompetent child. J Child Neurol. 2012;27(4):532-5.

18 Swartzentruber S, Rhodes L, Kurkjian K, Zahn M, Brandt ME, Connolly P, Wheat LJ. Diagnosis of acute pulmonary histoplasmosis by antigen detection. Clin Infect Dis. 2009;49(12):1878-82.

19 Stevens DA, Diagnosis of fungal infections: Current status J Antimicrob Chemother. 2002;49 Suppl 1:11-9.

20 Wiggins GL and Schubert JH. Relationship of Histoplasmin Agar-Gel Bands and Complement-Fixation Titers in
Histoplasmosis J Bacteriol. 1965;89(3):589-96.

21 Sandhu GS, Kline BC, Stockman L, Roberts GD. Molecular probes for diagnosis of fungal infections. J Clin Microbiol. 1995;33(11):2913-9.

22 Tang YW, Li H, Durkin MM, Sefers SE, Meng S, Connolly PA, et al. Urine polymerase chain reaction is not as sensitive as urine antigen for the diagnosis of disseminated histoplasmosis. Diagn Microbiol Infect Dis. 2006;54(4):283-7

23 Nosanchuk JD, Zancopé-Oliveria RM, Hamilton, AJ, Guimaraes. Antibody Therapy for Histoplasmaosis. Front Mircobio. 2012;3:21.

24 Histoplasmosis among Travellers. Avaiklable at http://www. gideononline.com/2008/12/19/histoplasmosis-amongtravelers/. Accessed May 26, 2013.

25 Griffin, SW, Kellogg CA, Shinn EA. Dust in the wind: Long range transport of dust in the atmosphere and its implications for global public and ecosystem health. Global Change \& Human Health. 2001;2(1):20-1.

The peer-reviewed Clinical Practice Section seeks to publish case studies, reports, and articles that are immediately useful, are of a practical nature, or contain information that could lead to improvement in the quality of the clinical laboratory's contribution to patient care, including brief reviews of books, computer programs, audiovisual materials, or other materials of interest to readers. Direct all inquiries to Perry Scanlan, PhD, MT(ASCP), Medical Technology, Austin Peay State University, Room D212, Sundquist Science Complex, Box 4668, Clarksville TN 37044. Clinical Laboratory Science encourages readers to respond with thoughts, questions, or comments regarding these articles. Email responses to westminsterpublishers@comcast.net. In the subject line, please type the journal issue and lead author such as "CLIN LAB SCI 27(1) RE CARAMARA". Selected responses may appear in the Dialogue and Discussion section in a future issue. Responses may be edited for length and clarity. We look forward to hearing from you. 